LETTERS

\title{
Re: Underuse and Overuse of Osteoporosis Screening in a Regional Health System: A Retrospective Cohort Study
}

\author{
Robert Ferrari, M.D., M.SC. (Med)., F.R.C.P.C., F.A.C.P. \\ Department of Medicine and Department of Rheumatic Diseases, University of Alberta, Edmonton, Alberta, Canada.
}

J Gen Intern Med 31(2):155

DOI: $10.1007 / \mathrm{s} 11606-015-3451-y$

(c) Society of General Internal Medicine 2015

\section{Dear Editor,}

The publication by Amarnath et al. ${ }^{1}$ is an important contribution to the Choosing Wisely campaign insofar as the study clearly identifies where there is wasteful testing (and where in some cases more testing may be indicated). In this case, the authors examined whether guidelines are being followed for osteoporosis screening in women. As there is increasing data concerning how bone density scans should be optimally utilized, a number of groups have issued Choosing Wisely recommendations. In Canada, for example, the Canadian Rheumatology Association's Choosing Wisely recommendations include specific advice not to repeat dual-energy X-ray absorptiometry (DEXA) scans more often than every 2 years. ${ }^{2}$ The work of Amarnath et al. delves even deeper into the issue, especially as to whether younger women with few or no risk factors are having unnecessary DEXA scans in the first place. Part of the problem may be that there have long been guidelines for which the evidence base is weak but which have nevertheless encouraged the overuse of DEXA. As an example, current guidelines recognize osteoporotic fractures as a common and serious health problem among elderly men. ${ }^{3}$ However, an analysis published in 2007 indicated that it is likely not cost-effective to routinely screen men over the age of 65 for osteoporosis, contrary to guideline recommendations. ${ }^{4}$ Indeed, when one examines the prevalence of osteopo- rosis in unselected male cohorts aged $65-75$ in primary care, the prevalence may be too low to justify the routine bone density screening recommended for this population. ${ }^{5}$ Amarnath et al.'s work affirms the need to evaluate whether current guidelines are being followed, but we must also remember that not all guidelines are well founded. Research aimed at informing wise choices must evaluate not only how guidelines are being followed, but also whether these guidelines have sufficient evidence to support the guideline recommendations.

Corresponding Author: Robert Ferrari, M.D., M.Sc. (Med)., F.R.C.P.C., F.A.C.P.; Department of Medicine and Department of Rheumatic Diseases University of Alberta, 13-103 Clinical Sciences Building, Edmonton, Alberta, Canada T6G 2P4 (e-mail: rferrari@shaw.ca).

\section{REFERENCES}

1. Amarnath AL, Franks P, Robbins JA, Xing G, Fenton JJ. Underuse and overuse of osteoporosis screening in a regional health system: a retrospective cohort study. J. Gen. Intern. Med. 2015; doi:10.1007/s11606-015-3349-8.

2. Chow SL, Thorne C, Bell MJ, Ferrari R, Bagheri Z, Boyd T, et al Choosing wisely Canada. Canadian Rheumatology Association: five things physicians and patients should question. J. Rheumatol. 2015; doi: 10. 3899/jrheum. 141140.

3. Papaioannou A, Morin S, Cheung AM, Atkinson S, Brown JP, et al. 2010 clinical practice guidelines for the diagnosis and management of osteoporosis in Canada: summary. CMAJ. 2010;182:1864-73.

4. Schousboe JT, Taylor BC, Fink HA, Kane RL, Cummings SR, et al. Costeffectiveness of bone densitometry followed by treatment of osteoporosis in older men. JAMA. 2007;298:629-37.

5. Ferrari R. Prevalence of osteoporosis in men aged $65-75$ in a primary care setting. A practice audit after application of the Canadian 2010 guidelines for osteoporosis screening. Clin. Rheumatol. 2014. 